\title{
Tool Condition Monitoring when Hard Machining
}

\author{
Marek Vrabel' ${ }^{1, *}$, Miroslav Pal'o ${ }^{2}$, Mária Semanová ${ }^{3}$, Ildikó Maňková ${ }^{4}$, Jozef Trebuňa ${ }^{5}$ \\ Technical University of Košice, Faculty of Mechanical Engineering, Prototype and Innovation Centre, Letná 9, 04001 Kosice \\ Technical University of Košice, Faculty of Mechanical Engineering \\ Technical University of Košice, Faculty of Mechanical Engineering \\ Technical University of Košice, Faculty of Mechanical Engineering, Department of Computer Support of Technology \\ Technical University of Košice, Faculty of Mechanical Engineering
}

\begin{abstract}
Article presents results of research activities in the area of the cutting tool condition monitoring using force signals as indices of tool wear and tool failure when hard turning. Cutting force authentically reflects changes in the tool during cutting with good accuracy. Relationship between cutting force and wear depends on work-piece/cutting tool interface and on changes of cutting conditions. Therefore, modelling as well as monitoring of tool wear is quantitative different for each work-piece/cutting tool interface and highly sensitive from cutting conditions changes, which obstruct their mutual comparison. The passive (radial) force became the largest among the three force components when cutting of hardened steel. However, the most sensitive to the changes of flank and nose wear was the mean feed force component although the passive force indicates significant increase, too. The character of dynamic value of force signal change when damage of cutting tip is presented.
\end{abstract}

Keywords: hard turning, tool condition monitoring, force signals, cutting tool wear.

\section{Introduction}

The monitoring of the cutting process or more precisely the monitoring of the tool condition in the production process represents one of the solutions related to sustainable development and sustainable production. The tool, as an active element of the cutting process, significantly affects the costs for machining and for the quality of produced parts. Modern cutting materials enable the use of high cutting speeds. The increase of the cutting speed causes that the costs for production, expressed by means of the costs for tools and machines have a steeper shape of the curve for expensive CNC machines than in the case of traditional machining methods. The monitoring of the tool condition and further phenomena related to the cutting process in automatic production, which is more demanding from the viewpoint of the operation; belong to the main requirements in order to provide for its reliable operation. A trouble-free operation of automatic production systems can be provided, apart from other things, by appropriate prediction based on the detection and regulation of the cutting process $[1,2]$. This means the observation, scanning and evaluating (monitoring) of the effects of the cutting process, such as the cutting force, temperature, system vibration, chip forms and breaking, damage to the tool, quality of surface and accuracy of workpiece dimensions. The monitoring of these quantities helps to optimise the course of the cutting process which, from the view of a trouble-free operation of the production system, should provide for a suitable shape of the emerging chip (segmental, serrated), eliminate the occurrence of built-up edge, the occurrence of vibration and increased wear/damage of the machine. The monitoring and prediction of the tool condition through the quantities of the process, such as the cutting force, vibration and acoustic emission, output and spindle torque belong to the research areas preferred in the

* Corresponding author: Marek Vrabel', E-mail address: marek.vrabel@tuke.sk 
world. Further development is focused on the fusion of sensors, their miniaturisation and integration into machine tools and tools with the ultimate purpose to construct fully automated smart production systems $[2,3,4]$.

The tool condition monitoring, as one of the dominant specialisations of monitoring, finds a positive response, when using superhard, but brittle tools made of cubic boron nitride and cutting ceramics for innovative machining technologies: high speed machining, HSC (High Speed Cutting), cutting/machining of very hard materials, HM (Hard Machining) and machining without cutting fluid, DM (Dry Machining).

Nowadays, among the wide range of metal based cutting tool materials such as high-speed steel and carbides, utilization of non-metallic cutting tool materials is about 7\% of the total amount of cutting tool materials on the world market. There are some fields such as aircraft industry, space industry and automotive industry where utilization of ceramics and cubic boron nitride takes about $40 \%$. The trend shows to the increasing of utilization of materials based on ceramics, cubic boron nitride and diamond depending on higher requirements of precision and high quality of machined surfaces when grinding quality surface finish can be obtained by turning $[3,5]$.

Wear of the tool affects the machining process productivity, quality of products, costs of tools and strategy of tool replacement [7]. Roughness of the machined surfaced, for example, can be the decisive factor for the determination of the time for the replacement of the tool for fine finishing. A reduction of costs and increase of cutting process productivity can be achieved by means of maximum use of the life period of the tool, and thus by extending the time period between two replacements of the tool. The above reasons are the driving force behind research and development of modern monitoring systems for cutting processes and for tool condition monitoring. Failures in the cutting process, which arise due to the wear of the tool are most frequently caused by the following $[8,9]$ :

- increased intensity of the wear of the tool, which causes various durability of the cutting edge and reduces the time period of uninterrupted operation of the tool;

- excessive wear of the cutting edge, which affects the dimension and shape accuracy of the machined surface;

- static or dynamic overload of the tool, which causes damage to the cutting edge by breaking, which can further damage the workpiece, tool holder or even the machine;

- type of used cutting tool material, tool geometry - incorrect shape can produce undesired chip (continuous rolled, ribbon-like...) damaging the continuity of automatic machining; and its removal is very difficult.

The research of the tool condition monitoring during machining is focused on the evaluation of the damage to the tool in the process of cutting and on the identification of various stages of the cutting edge wear $[1,5,9]$. The causes and forms of the wear of the cutting wedge are, to a considerable degree, understood and explained, however, the complexity of the process as such causes that the detection of the damage to the tool during the cutting process, so-called on-line monitoring is still not considered as wholly resolved $[10,11]$. The occurrence of various tool wear form is not parallel and the individual forms of wear mostly depend on the machining conditions, type of cutting material and workpiece.

VDI 73 [6] lists a number of general criteria for classification of process monitoring systems. Process monitoring systems may be intermittent (offline) or continuous (online). Moreover, a difference is made between directly and indirectly measuring systems. Direct methods, although they are highly accurate, are not suitable for the operation conditions. Indirect methods of scanning of gradual wear of the tool include the measurement of the cutting process quantities, which are sensitive to the wear of the tool. Indirect methods are more suitable for the monitoring of the tool condition, but they are less sensitive than direct methods. Their disadvantage is the necessity of calibration for the particular process parameters. Currently, the high level of reliability of modern electronics (sensors), as well as high-performance computer technology, to a large degree contributes to the use of indirect methods of tool condition monitoring. Indirect monitoring quantities also include the engine capacity of the machine tool, spindle torque and electric current. The most frequently used monitoring quantities undoubtedly include the cutting force and its components. This is due to good availability of the sensors of the cutting forces as well as methods of their evaluation. Several studies of cutting tool monitoring $[8,9,10]$ agree that the components of the cutting force most reliably reflect the condition and the changes in the condition of the cutting 
edge.

The force, despite numerous limitations, seems as a suitable parameter for indirect monitoring of the tool condition in the cutting process [11]. The information content of the force in the theory of metal cutting can be viewed from two viewpoints:

- force as a static phenomenon; mean values of the force serve for the calculation of the output, stiffness of tools, for the specification of model dependencies on cutting parameters, wear and static thresholds in decision making processes of monitoring;

- force as a dynamic phenomenon; information value of the force is via time records and frequency spectra; and it reflects the dynamics of the cutting process progress.

\section{Experimental set up and cutting conditions}

The machining tests were performed on bearing steel (DIN 16MnCr5) with hardness of $60 \mathrm{HRC}$. Bar of the material with $110 \mathrm{~mm}$ in diameter and about $250 \mathrm{~mm}$ in length was used for longitudinal turning. Time series record of force components for different cutting tool materials were registered using following experimental conditions:

1. Cubic boron nitride insert: Type KOMPIZIT 01 hardness $5500 \mathrm{HV}$, heat conductivity $60-80 \mathrm{~W} / \mathrm{m} . K$, density $3400 \mathrm{~kg} / \mathrm{m}^{3}$, Cutting inserts SNGN 120408, chamfered edge, nose radius $0,1 \mathrm{~mm}$, tool holder type $2020 \mathrm{K01}$, main approach angle $45^{\circ}$, negative rake angle $6^{\circ}$, negative inclination angle $-6^{\circ}$, cutting speed $v_{c}=90,120,160 \mathrm{~m} / \mathrm{min}$; feed per revolution $f=0.102 \mathrm{~mm}$; depth of cut $a_{p}=0.15 \mathrm{~mm}$.

2. Cubic boron nitride: Type BN PB2, low CBN content, hardness $5100 \mathrm{HV}$, heat conductivity $65-70 \mathrm{~W} / \mathrm{m} . \mathrm{K}$, density $3200 \mathrm{~kg} / \mathrm{m}^{3}$, Cutting inserts TNMA 160408, chamfered edge, nose radius $0.8 \mathrm{~mm}$, tool holder type 2525 M16PTTNR main approach angle $45^{\circ}$, negative rake angle $6^{\circ}$, negative inclination angle $-6^{\circ}$, cutting speed $v_{c}=90$, $120,160 \mathrm{~m} / \mathrm{min}$; feed $f=0.102 \mathrm{~mm}$; depth of cut $a_{p}=0.15 \mathrm{~mm}$.

The tool holder was mounted on tri-axial piezoelectric dynamometer Kistler, which was mounted on the turret faceplate of the lathe. The dynamometer, with charge amplifier and with a data acquisition system consisting of $A / D$ transducer with eight analogue inputs and connected with computer, where the data were permanently stored for further off-line analysis, was used to measure three components of forces, cutting force $F_{c^{\prime}}$ passive force $F_{p}$ and feed force $F_{f}$. Sampling time was $200 \mu$ s. Experimental work was designed to obtain data for sharp tools and different modes of progressive wear. Static and dynamic entities of the sampled force were extracted as the mean and oscillatory components, respectively, and analysed at first as mean (static) value for comparative evaluation, latter in time and frequency domain from which features sensitive to tool wear were identified.

\section{Results and discussion}

\subsection{Relationship between force components and tool wear}

The force is an important information source and it reliably reflects the tool condition in the cutting process. On the other hand, it is to be critically assessed that $[11,13]$, even if it is accepted that the force and it components bear high information value about the cutting process, the force is, at the same time, a phenomenon, which is strongly affected by numerous parameters (cutting conditions, tool geometry, cutting tool materials, workpiece materials, form of tool wear etc.), which affect the progress of the change of its value. This means that if the influence of wear on the change of the overall cutting force and its components is to be monitored, identical conditions are to be provided in order to be able to compare the results and determine appropriate limitation and constant conditions.

If the impact of the change to the geometry of the tool, cutting environment, cutting speed and cutting parameters is considered as stabilised and constant, then the effect of wear (prevailing wear of the flank face $V B_{B^{\prime}} V B_{N^{\prime}}, V B_{C}$ ) is manifested on the force components by their increase/decrease. Usually, increased wear is manifested as the increase of the force components.

The feed component and the passive component are more sensitive than the cutting force component in relation to the damage of the tool, which is manifested as breaking, damage and plastic deformation of the tool point as well as gradual wear of the flank face. The passive component and the feed component enable more accurate recognition of the tool wear. Both components are typical of the highest increase of the value of the force (mean values).

Experimental studies show that the components of the force react in a different way to different forms of wear, which can occur on the cutting edge. For example, the feed force is not prone to the creation of a crater on the rake face, but the feed and passive forces are more affected by the wear of the tool than the cutting force $[14,15]$.

The static (mean) value of force signals increase as wear level increase, Figure 1. Experiments have been shown different response of force components to 
the various wear form occurring on the tool. Figure 1 shows the percentage increase in components of force for worn tool against the new tool.
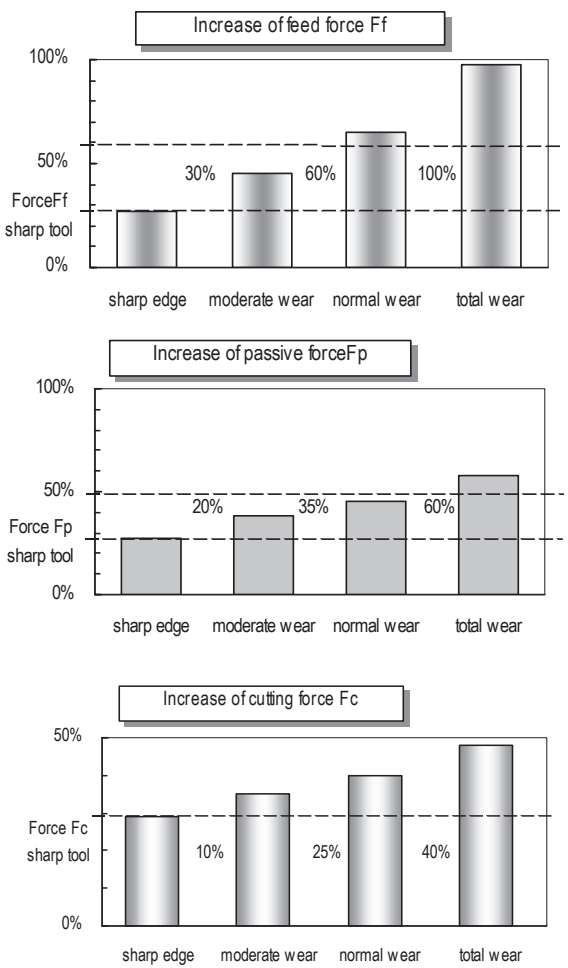

Figure 1: Assumed force components increase depending on progressive flank wear level.

The cutting force component, however, is not as sensitive to progressive wear as the others are feeding and passive components [11]. Main force is insensitive to crater wear; whereas the feed and passive forces may be influenced more by tool flank wear than the cutting force. Both the feeding and passive components are more sensitive than the cutting component in detection tool chipping and breakage. These components increase suddenly at the instant of breakdown of the cutting edge mainly in dynamic manner. The cutting force and the feed force seem to monitor the condition of the tool totally. So it is believed that these two forces should be used to predict the value of tool wear at any instant $[8,14]$.

The cutting force $\mathrm{Fc}$ is more sensitive to the instability of cutting process and it reacts by the increase of the amplitude of oscillations of the dynamic component, Fig. 2. Figure 2 shows power spectral density (PSD spectrum) of cutting force for different progressive flank wear.

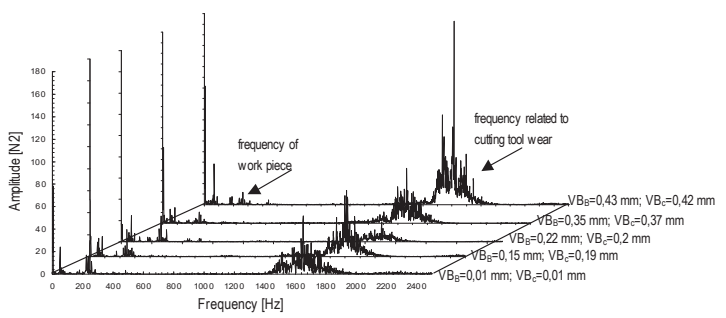

Figure 2: Power spectral density of cutting force.

The frequency peaks at $1.5 \div 1.85 \mathrm{kHz}$ were the most sensitive to wear levels, which coincided with the dynamometer resonant frequency. From the spectra obtained, it was possible to establish a distinct difference in signal characteristics when cutting was performed with a sharp insert compared to that of various wear stage. At the beginning of the cutting process, the amplitude of dynamic oscillations of the cutting force is in the direction of the z-axis, i.e. of the cutting force, small, because the contact between a sharp cutting edge and workpiece is minimal. The area of wear on the flank face of the tool is gradually getting larger in the cutting, which causes a gradual increase of the amplitude of dynamic force oscillation. The amplitude of oscillations markedly grows with the increasing wear of the flank face. The effect of the cutting temperature on the contact area causes the change in the intensity of wear and the cutting edge is being worn out faster.

\subsection{Tool condition monitoring when hard machining}

The overall force in the turning operation, in a simplified way, broken down into its components: tangential/cutting force $F_{c^{\prime}}$ in the direction of the $z$-axis, radial/passive force $F_{p^{\prime}}$ in the direction of the $y$-axis, axial force/feed force $F_{f \prime}$ in the direction of the $x$-axis. The components are influenced especially by the chip cross-section, by cutting speed, hardness of worked and cutting tool materials, geometry of tool, cutting environment. The break-down of forces for the turning of quenched steel by the innovation technology of hard machining, can serve as an example. The conditions of machining for the innovative technology hard machining (HM) are different from for conventional turning $[12,16]$. Small cutting depths are used $\left(a_{p}<r_{n}\right)$, smaller than the radius of the cutting edge roundness $r_{n}$. The 
values of the cutting depth ap, feed $f$ and cutting edge roundness $r n$ are characteristic quantities for the HM technology which can successfully replace the grinding of quenched materials. As very small cutting depths $\left(a_{p}<r_{n}\right)$ and rather large cutting edge roundness $r n$ are used, the chip cross-section of the layer to be cut is spread on a small part of the cutting edge in the area cutting edge roundness. The ratio of the components of the overall force is different from conventional turning, in the case of which the forces decrease in a sequence $F_{c}>F_{p}>F_{f \prime}$ Figure $3 a$. The sequence $F_{p}>F_{c}>F f$ is typical for the HM technology, Figure $3 b$.

The above fact is also reflected in the monitoring of the behaviour of the force, where the component $\mathrm{Fp}$ is of decisive character for the wear/damage to the tool. Small chip cross-sections extremely increase the load on the cutting edge in the area of the contact tool/workpiece. For this reason, the mechanical and thermal load on the cutting edge requires such materials, which are chemically inert and which preserve their high hardness even with high cutting temperatures $\left(200 \div 1200^{\circ} \mathrm{C}\right.$ ).
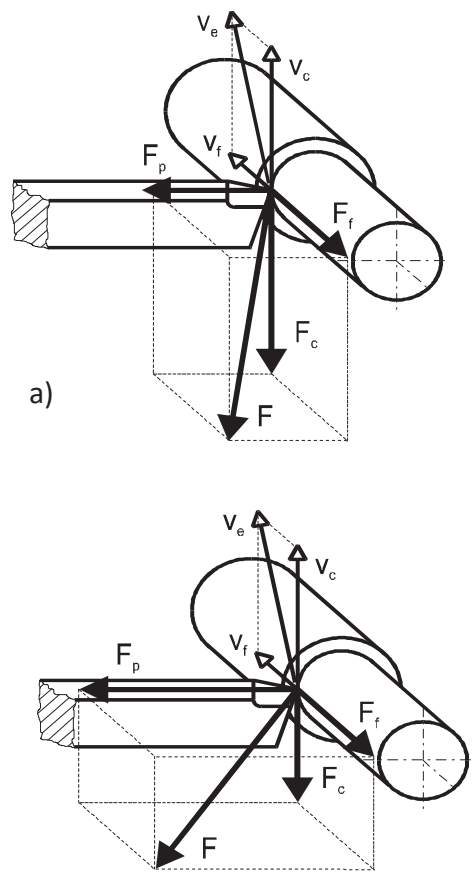

b)

Figure 3: Force components for a) conventional turning --7) hard turning.
Cutting tool materials made of ceramics and cubic boron nitride (CBN) are used for HM. The dominant factor of the wear of the above types of cutting materials is represented by mechanical and thermal load on the contact areas between the tool and the workpiece. Relatively high brittleness and low transverse rupture stress are disadvantageous characteristics with regard to the high hardness of these materials. The above implies that a sudden damage of the cutting edge by chipping, crater a part of the active edge or brittle damage the cutting edge is frequent in the cutting process. CBN tools are rather rare with regard to their high purchase price and specific use [12]. The prevailing sign of the CBN tools wear when cutting materials with high hardness over $55 \mathrm{HRC}$ is represented by mechanical load and chemical wear due to high temperatures in the cutting process, Fig 4 a, b, c.

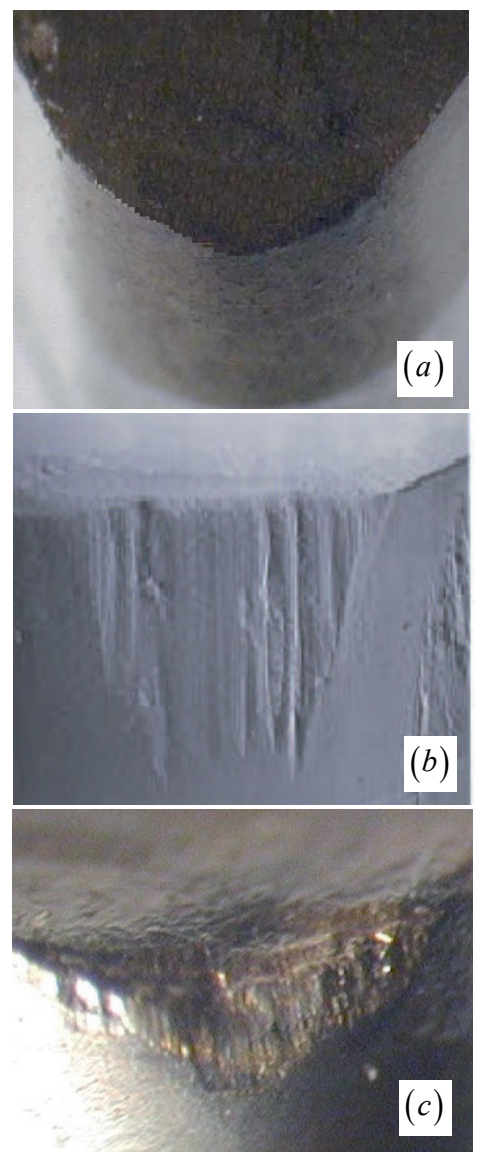

Figure 4: Wear forms for BN inserts (type PB2 low content of CNB) when turning hardened steel $16 \mathrm{MnCr} 5, a$ ) new insert, b) chemically activated wear on flank face, c) damage of cutting edge, magnification 50x. 


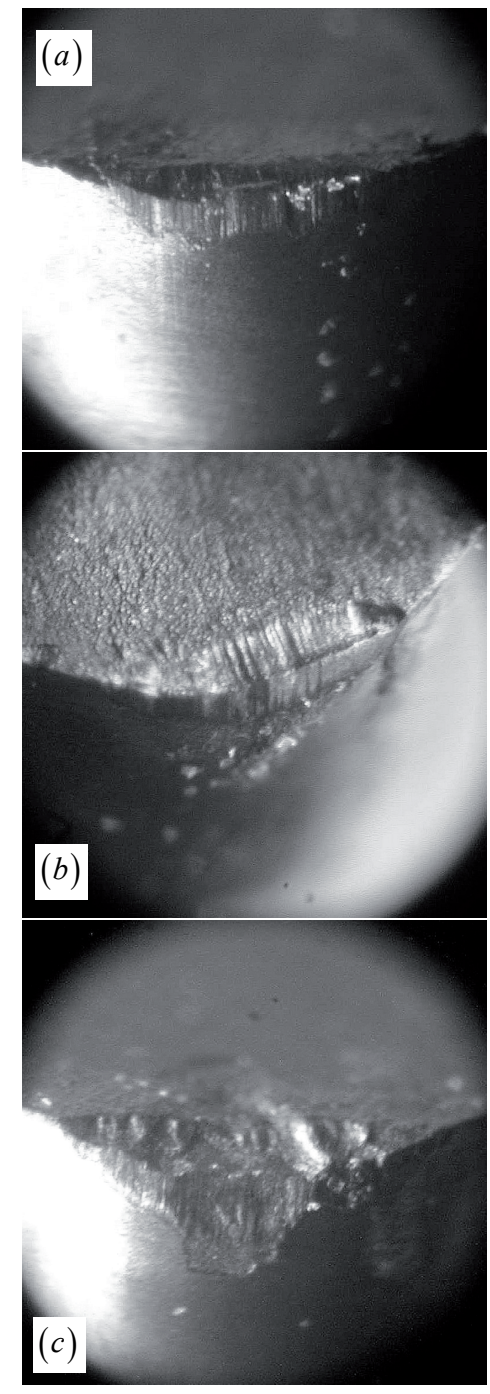

Figure 5: Wear forms for CBN inserts (type PB21) when turning hardened steel $16 \mathrm{MnCr} 5$ a) typical flank wear, b) crater on the rake face, c) damage of tool nose, magnification 50x.

A sudden breaking of the cutting edge or more precisely the chipping of the cutting edge is also not negligible. The wear of the main flank area is measurable by values $V B_{B^{\prime}} V B_{\text {max }^{\prime}}, V B_{N^{\prime}}, V B_{C^{\prime}}$ prevailing form of wear Fig. 5 a, b, c and Fig 6 a, b, c. A built-up edge (typical for lower cutting speeds vc approx. 60 $\mathrm{m} / \mathrm{min}$ ) or creation of a crater wear in close of the cutting edge can be observed in the case of CBN tools Fig. 5b and Fig 6b.

\subsection{Influence of wear on dynamic value of force signal when hard machining}

The changes of character of dynamic signal of force components when damage of cutting tip were

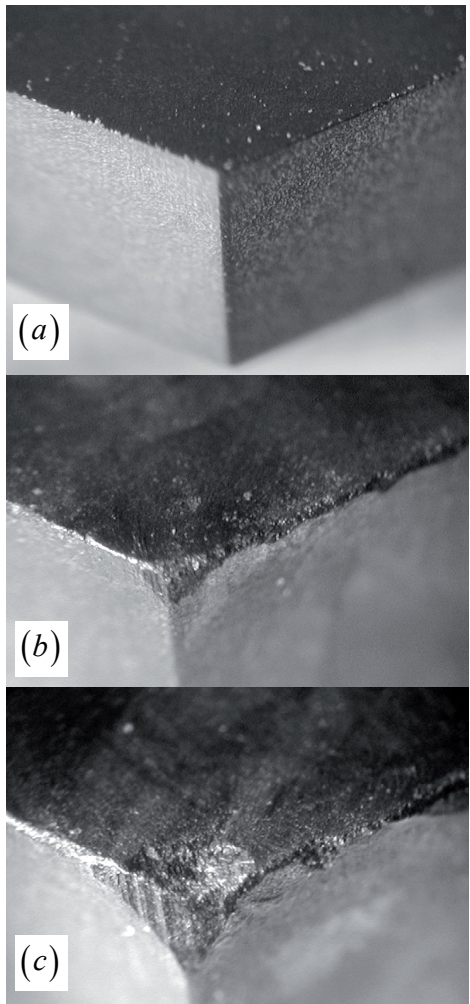

Figure 6: Wear forms of BN inserts (type Kompozit 01) when finish turning of hardened steel $16 \mathrm{MnCr} 5$ a) new insert, b) chipping on main cutting edge c) mechanically induced wear on flank face and crater wear.

recorded. Parts of observed and monitored dynamic value of force components time signals there are in Figures 7, 8, 9. Dynamic force component in time domain were scanned for sharp cutting edge and for damaged cutting tips only.

Figure 7 shows a typical variation of force components scanned by dynamometer, for overall tool damage. The tool bit CBN broke in the first seconds of cutting and at the same time a part of the pad of tungsten-carbide too, which the pad is mounted broke off as well. The increase of force components at the moment of break is multiple. Then there is a sudden decrease caused by the loss of contact between the tool and the workpiece.

Damage due to excessive wear/break of tool (e.g. damaged holders for the clamping of tool tip, workpiece or machine components) occur only then, if several further revolutions are performed with the damaged machine tool. There were cases with holders damaged as much as $3 \mathrm{~mm}$ under 

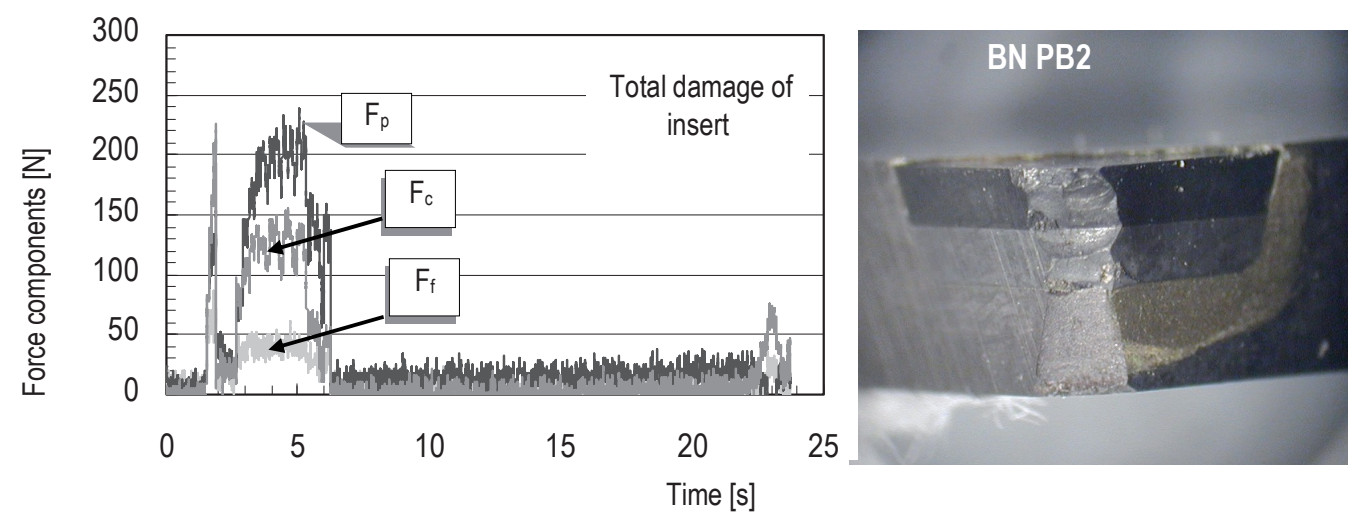

Figure 7: Variation of force components during tool breakage in the first seconds of cutting. (cutting condition $v_{c}=160 \mathrm{~m} / \mathrm{min}, f=0.102 \mathrm{~mm}, a_{p}=0.15 \mathrm{~mm}$ )
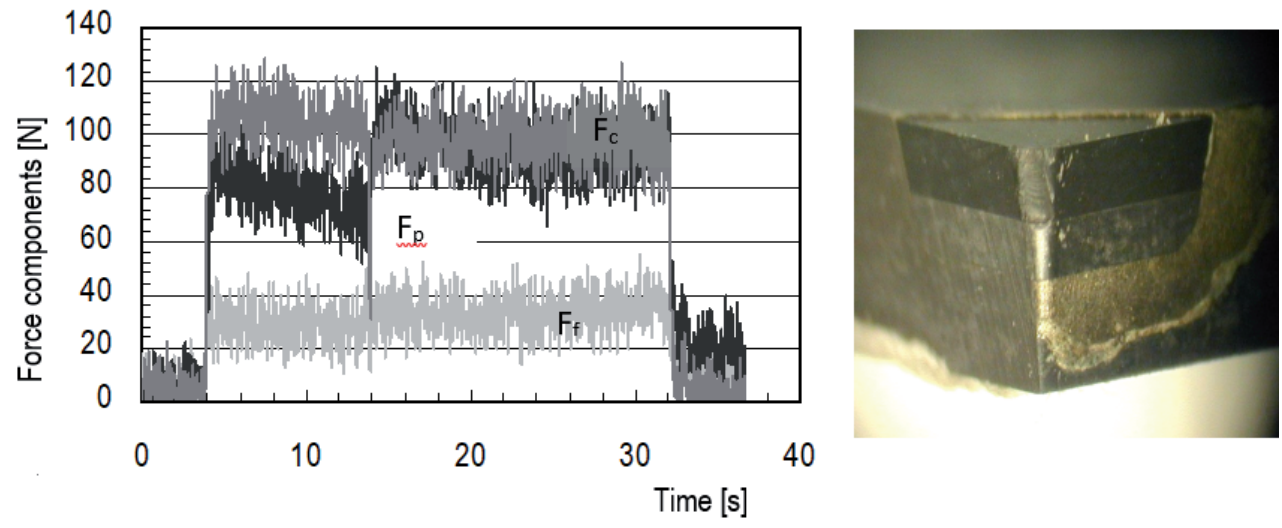

Figure 8: Variation of force components during tool breakage. (cutting condition $v_{c}=120 \mathrm{~m} / \mathrm{min}, f=0.102 \mathrm{~mm}, a_{p}=0.15 \mathrm{~mm}$ )

component, which is in this case most sensitive to the dynamics of cutting and tool damage.

cutting edge.

The recognition of such a condition is very difficult which is confirmed by a variety of research studies. The difficulty is because the breakage or other damage to the tool (apart from the gradual wear of the flank face area) is manifested in a different way on the signals of monitoring indicators. As an example Figures 8, and Fig 9 contains the variation of time records of force components during turning of quenched steel, class $16 \mathrm{MnCr} 5$ (60 HRC) by means of tools made of cubic boron nitride.

The comparison was made with the variation for a sharp tool without any visible damage in the first seconds of cutting and variation of sudden break or other cause of damage to the active part of the cutting edge (from author's results). Variations of forces are filtered and processed by means of moving averages in MS Excel.

As this is the cutting of hard materials, the highest values are achieved in the case of the passive force

The variation of force is completely different in the case of longitudinal turning by means of CBN tool, Fig. 9. The cutting edge was damaged approx. after 40 seconds of cutting. This was manifested by a slight decrease of force components at the moment of damage. The conditions of action have changed, however, the process of cutting has continued up to the moment when the force Fp increased, probably due to the damaged point (approximately after two minutes of cutting).

Enormous increase of component Fc (approximately after four minutes of cutting) and the process of cutting stopped signalled a complete loss of cutting power of the wedge. Any visible signs on the workpiece (shiny areas, notches) have not manifested tool damage during the process of cutting. It was only detected during roughness measuring. There was deterioration of roughness measured in the area with increased component Fp (approximately after 120 seconds), Fig. 9. 


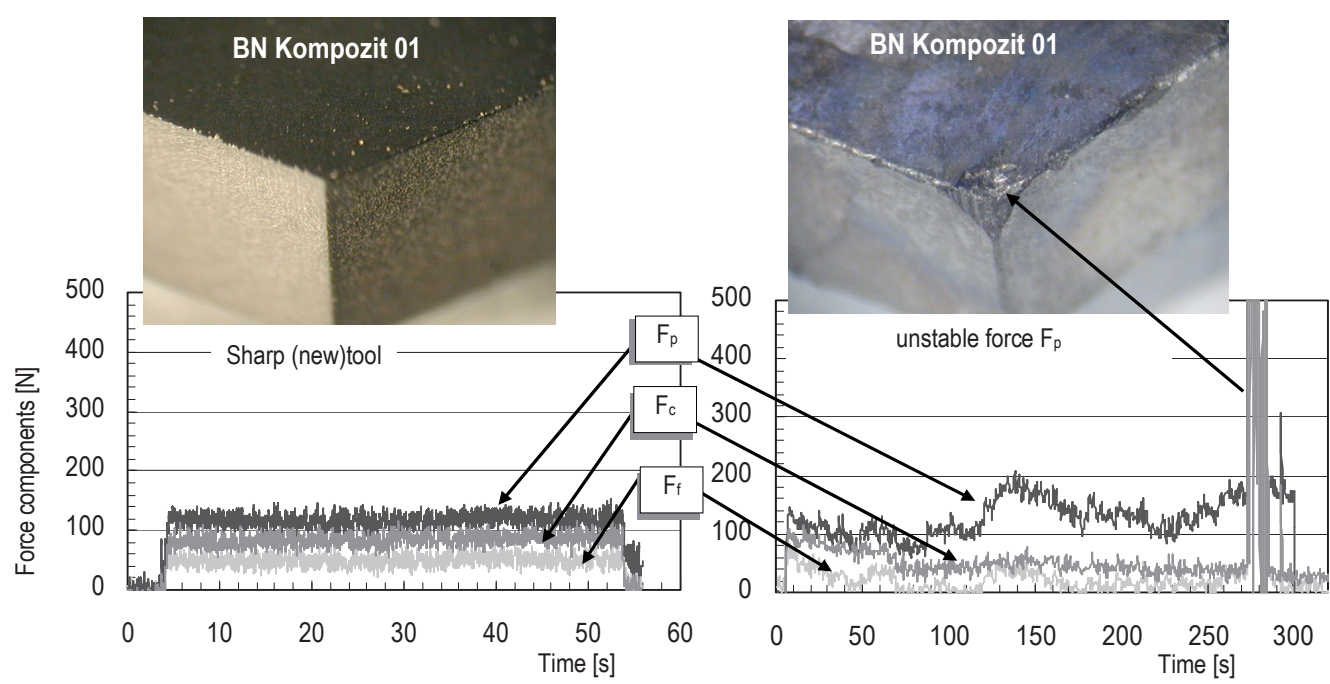

Figure 9: Variation of force for a sharp and for gradually worn and damaged CBN tool of Komposite 01 type.

(cutting condition $v_{c}=90 \mathrm{~m} / \mathrm{min}, f=0.102 \mathrm{~mm}, a_{p}=0.15 \mathrm{~mm}$ )

\section{Conclusions}

Development of dynamic value of force signals in time domain when damage of cutting tip show the passive force importance whiles the cutting and feed force variation is less significant. Spectral analysis of cutting force signal through FFT algorithm shows the possibility to establish the difference between sharp and worn tool and apply it for tool condition monitoring.

In hard turning of steel, the passive (radial) force became the largest among the three force components. However, the most sensitive to the changes of flank and nose wear was the mean feed force component although the passive force indicates significant increase, too.

Data acquisition and various forces signal collection in our research activity is oriented to create so called "models" of force signals when cutting with sharp tool to compare with signals of various type of tool edge damage. This "models" of time signals will be used for learning process in decision-making part of tool condition monitoring system at our workplace.

Any attempts at operating so-called intelligent production systems require the development of highly flexible monitoring strategies, which are able to adapt to various configurations of production machines and processes. What is more and more important is the integration of monitoring process and control system of machining tool, which is able, thanks to adaptive control (limiting ACC or optimising ACO) react faster to a sudden change of cutting conditions. The use of multi-sensor configurations with intelligent decision making processes (neuron networks, fuzzy decision making) for a single process is a part of development, which heads towards intelligent monitoring systems. Although the notion "intelligent monitoring system" has no uniform interpretation and it is explained in a different way in many publications. On one hand it is connected with the use of artificial intelligence methods for decision making, on the other hand, it is understood as an integral part of hardware and software of modern CNC machines, which work with graphic interface of operation control system.

\section{Acknowledgments}

This work was supported by the project VEGA 1/0219/18" Development of intelligent monitoring system for zero-defect production of irreplaceable parts". and partly by project KEGA 048TUKE-4/2020 "Web/base training to support experimental skills in engineering testing".

\section{References}

1. LEOPOLD, J.: 1999, Werkzeuge fur Hochgeschwindigkeitbearbeitung. C.H. Springer Verlag, Munchen

2. TETI R, JEMIELNIAK $K$, ODONNELL G, DORNFELD D. Advanced Monitoring of Machining Operations. CIRP Annals- Manuf.Technol. 2010, 59, 717-739

3. JEMIELNIAK, K.: 2002, Automatic Diagnosis of Machining Process and Tool Condition, WPW Warszawa (in Polish) 
4. INASAKI, I.; BLUM, T.: A Study on Acoustic Emission from the Orthogonal Cutting Process. ASME Journal of Engineering for Industry, Vol. 112, August 1990, pp. 203-211

5. BYRNE, G.; DORNFELD, D.; INASAKI, I.; KONIG, W.; TETI, R.: Tool Condition Monitoring - The Status of Research and Industry Application. Annals. of the CIRP Vol.44/2/1995, pp.541 -567

6. VDINDE Richtlinie 2006-Blatt 2 (1973): MetrologieGrundbegriffe, VDI Verlag Düsseldorf.

7. DANAl, K., ULSOY, A., G.: A Dynamic state Model for Online Tool Wear Estimation in Turning. ASME Journal of Engineering for Industry, Vol. 109, November 1987, pp. 396399.

8. DIMLA, D.E.: Sensor Signals for Tool Wear Monitoring in Metal Cutting Operations - A Review of Methods. Int. J. Mach.Tools Manufact. Vol.40 No 9, 2000 pp.1073-1098

9. DU, R.; ELBESTAWI, M.A.; WU, S.M.: Automated Monitoring of Manufacturing Processes. part 1: Monitoring Methods, ASME J. of Engineering for Industry, Vol 117, May (1995) pp. $121-132$

10. F.KLOCKE, GIERLINGSS, BROCKMANN M, SAGEC, VESELOVAC D. Adaptive Control of Manufacturing Processes for a New Generation of Jet Engine Components. CIRP - ICME Capri, 2010

11. CHOUDHURY, S. K.; KISHORE, K. K.: Tool Wear Measurement in Turning Using Force Ratio. Int. J. Mach.Tools Manufact. Vol.40 No 10, 2000 pp.899-909

12. J. KUNDRAK, B. KARPUSCHEWSKI, K. GYANI, Accuracy of hard turning, Journal of Materials Processing Technology. 202 (2008) 328-338.

13. C.H. LAURO ET AL:: Monitoring and processing signal applied in machining processes - A review, Measurement, 58 (2014) 73-86,

14. MAŇKOVÁ, I.; SALANCI, S.: Cutting Tool Wear and Failure Identificaton via Force Signals. Archiwum technologii maszyn i automatizacji ISSN 1233-9709 Vol.20, Nr 2, Poznan 2000, str. 50-58

15. MAŇKOVÁ, l.: Monitoring of Cutting Force and Tool Wear when Hard Turning. Production processes and systems. HU ISSN 1215-0851 Vol 1 (2002), Nr 1, Miskolc 2002, str. 75-80

16. ZEBALA, W., PLAZA, M.: Comparative study of 3-and 5-axis CNC centers for free-form machining of difficult-to-cut material. International Journal of Production Economics, 158 (2014) 345-358 